\title{
Controlling the microdomain orientation in block copolymer thin films via cross-linkable random copolymer neutral layer
}

\author{
Seyong Kim ${ }^{1,4}$, Hyun Suk Wang ${ }^{1,4}$, Youngson Choe ${ }^{2}$, Soo-Hyung Choi ${ }^{3}$ and Joona Bang ${ }^{1}$ \\ Block copolymer (BCP) thin films are capable of producing periodic nanoscale features that are hardly accessible by \\ conventional 'top-down' lithography. Such is the potential of BCP thin films that many research groups are intensively studying \\ this field. Notwithstanding their advantages, BCP thin films suffer from an inherent tendency to produce microdomains parallel \\ to the substrate due to selective wetting. To date, various approaches to induce perpendicular orientation have been reported \\ using surface neutralization, solvent annealing, external fields and nano-fillers. Of these approaches, surface neutralization using \\ random copolymers is the most widely used because of its straightforward and intuitive methodology. Surface neutralization \\ alleviates the preferential interaction of one block with the substrate, and thus selective wetting, which enables the formation of \\ microdomains perpendicular to the substrate. In this review, advances in surface neutralization are covered by introducing four \\ efficient cross-linkable random copolymers incorporated with benzocyclobutene, glycidyl methacrylate, azide and ketene
} functional groups.

Polymer Journal (2016) 48, 333-340; doi:10.1038/pj.2016.9; published online 10 February 2016

\section{INTRODUCTION}

Block copolymer (BCP) self-assembly has been attracting considerable attention as a simple route to overcome the limitations of conventional 'top-down' lithography. ${ }^{1-4}$ In particular, BCP thin films can provide nanometer-scale scaffolds and templates for various applications, such as nanolithography, microelectronics, nanoreactors and separation membranes. ${ }^{5-12}$ Compared with the conventional 'top-down' lithography, BCP lithography provides cost-effective and simple access to nanoscale structures in the size regime of $\sim 5 \mathrm{~nm}$ to $\sim 100 \mathrm{~nm}$ with considerably uniform spheres, cylinders, bicontinuous gyroids, and lamellae by controlling the BCP molecular weight, architecture, dispersity and segmental interactions, as well as the volume fraction of each block. ${ }^{12-18}$

One of the challenging issues for BCP lithography is controlling the orientation of BCP microdomains on the substrate. In the case of diffusion barriers or line transfer lithography, cylinders or lamellae parallel to a substrate are required, while nanoporous membranes and post-pattern transfer templates require perpendicularly oriented microdomains. The orientation of BCP thin films is affected by interfacial interactions between the $\mathrm{BCP}$ and the substrate or the BCP and the free surface. ${ }^{3,4,17-24}$ In most cases, one of the blocks has preferential interactions with the substrate due to a lower surface energy, causing the block to be positioned selectively at the inter-material interface, thus inducing parallel orientation. For example, when a thin film of polystyrene-block-poly(methyl methacrylate) ( $\mathrm{P}(\mathrm{S}-b-\mathrm{MMA}))$ is fabricated on a silicon substrate, the microdomains show orientations parallel to the substrate owing to the preferential interaction between PMMA blocks and the silicon oxide layer. ${ }^{25-27}$ Accordingly, when an orientation perpendicular to the substrate is desired, the preferential interactions should be overcome. A number of strategies to control the orientation of microdomains - in particular, cylinders and lamellae-have been demonstrated, such as surface neutralization, ${ }^{24,28-33}$ solvent annealing, ${ }^{34,35}$ the use of electric fields, ${ }^{36}$ and topologically roughened surfaces. ${ }^{37,38}$ In addition, recent studies have also taken into account the free surface behavior of block copolymer thin films by incorporating removable top coats ${ }^{39,40}$ and surface-tailored nanoparticles ${ }^{41-45}$ to control the microdomain orientation of the BCP thin films. The advances in surface neutralization have expanded the choice of BCPs for fabricating perpendicularly oriented BCP thin films.

Among these approaches, the most widely used is neutralization of the substrate using $\mathrm{P}(\mathrm{S}-r$-MMA) random copolymers to control the polymer/substrate interaction. There have been numerous studies on variations of this approach because of its simplicity and high

${ }^{1}$ Department of Chemical and Biological Engineering, Korea University, Seoul, Republic of Korea; ${ }^{2}$ Department of Chemical Engineering, Pusan National University, Kumjeong-ku, Busan, Republic of Korea and ${ }^{3}$ Department of Chemical Engineering, Hongik University, Seoul, Republic of Korea

${ }^{4}$ These authors contributed equally to this work.

Correspondence: Professor S-H Choi, Department of Chemical Engineering, Hongik University, Seoul 121-791, Republic of Korea.

E-mail: shchoi@hongik.ac.kr

Professor J Bang, Department of Chemical and Biological Engineering, Korea University, Anam-dong 5-1, Sungbuk-gu, Seoul 136-713, Republic of Korea.

E-mail: joona@korea.ac.kr

Received 12 November 2015; revised 26 December 2015; accepted 4 January 2016; published online 10 February 2016 
reproducibility. Russell and Hawker first reported the approach using hydroxy-terminated $\mathrm{P}(\mathrm{S}-r$-MMA) to form random copolymer brushes on a silicon substrate as a neutral layer. ${ }^{20-24}$ They found that the interfacial interactions between the random copolymer layer and both blocks (that is, PS and PMMA) were balanced when the mole ratio of styrene/MMA in the random copolymer was 58/42, leading to a perpendicular orientation of the microstructures. ${ }^{46,47}$ In addition, based on this result, they demonstrated that the microdomain orientation of the cylinder- or lamellae-forming $\mathrm{P}(\mathrm{S}-b-\mathrm{MMA})$ was affected by the film thickness, molecular weight and the composition of the $\mathrm{P}(\mathrm{S}-r$-MMA $){ }^{48}$ However, this approach is limited to substrates with oxide layers and requires a long processing time to anchor the hydroxy-terminated random copolymers to the oxide layer. To overcome these limitations, generalized surface neutralization approaches using a cross-linked random copolymer layer have been developed. ${ }^{28-33}$

In this review, we discuss recent progress on controlling the orientation of BCP thin films, particularly in terms of a generalized approach to surface modification via a robust and efficient crosslinking strategy. We first present a random copolymer of styrene and MMA with $\mathrm{BCB}$ incorporated along the backbone. The BCBfunctionalized $\mathrm{P}(\mathrm{S}-r$-BCB- $r$-MMA) can be thermally cross-linked to provide a 'random copolymer mat' as a neutral layer. Then, we describe more advanced types of random copolymers containing GMA or azido groups that can be cross-linked by both heat and UV irradiation. Last, a random copolymer with ketene-based chemistry that has recently been developed is presented.

\section{BCB-BASED CROSS-LINKABLE RANDOM COPOLYMER}

As a pioneering work on the general surface neutralization, the Russell and Hawker groups developed a cross-linkable random copolymer containing the thermally cross-linkable BCB unit shown in Figure 1a, $\mathrm{P}$ (S-r-BCB-r-MMA), which can generate a cross-linked neutral layer on various substrates and effectively modify the interfacial interactions between the BCP thin film and the substrate. ${ }^{28,29}$ Because the previous study reported that a 0.58 molar composition of styrene in $\mathrm{P}\left(\mathrm{S}-r\right.$-MMA) gives a neutral layer, ${ }^{23-25}$ the molar composition of styrene, $\mathrm{BCB}$ and $\mathrm{MMA}$ in the random copolymer was adjusted to $0.56,0.02$ and 0.42 , respectively, owing to the structural similarity between $\mathrm{BCB}$ and styrene. The synthesized $\mathrm{P}(\mathrm{S}-r$-BCB- $r$-MMA) random copolymer had $M_{\mathrm{n}}=35 \mathrm{~kg} \mathrm{~mol}^{-1}$ with $Ð=1.18$ (where $Ð$ indicates the dispersity, defined as $\oslash=M_{\mathrm{w}} / M_{\mathrm{n}}$ ), which corresponds to an average of seven $\mathrm{BCB}$ units per chain. The BCB cross-linking on a silicon wafer proved to be efficient, producing a cross-linked ultrathin film $\sim 10 \mathrm{~nm}$ in thickness after heating at $250^{\circ} \mathrm{C}$ for 10 min under a nitrogen atmosphere. The cross-linking efficiency was confirmed by a constant film thickness even after rinsing with toluene, a good solvent.

The effect of the cross-linked film thickness on the surface energy was also studied by homopolymer dewetting tests. Thin films of PS and PMMA homopolymers were coated onto the cross-linked $\mathrm{P}$ (S-r-BCB-r-MMA) films and subsequently thermally annealed to dewet the homopolymer films. From the contact angles of dewetted PS and PMMA on the random copolymer layer, it was confirmed that the interfacial interactions between PS/PMMA and the random copolymer layers are balanced. Consequently, $\mathrm{P}(\mathrm{S}-b-\mathrm{MMA})\left(M_{\mathrm{n}}=88 \mathrm{~kg} \mathrm{~mol}^{-1}\right.$, $Ð=1.03$, and $f_{\mathrm{PS}}$ (the volume fraction of PS in the $\left.\mathrm{BCP}\right)=0.72$ ) were spin casted onto silicon wafers that were coated with various thicknesses of a $\mathrm{P}(\mathrm{S}-r$-BCB- $r$-MMA) random copolymer layer and were thermally annealed at $170{ }^{\circ} \mathrm{C}$ for $24 \mathrm{~h}$ under vacuum. As shown in Figure 2, when the thickness of the cross-linked P(S- $r$-BCB- $r$ MMA) film is larger than $\sim 5.5 \mathrm{~nm}$, perpendicularly oriented cylinders of the $\mathrm{P}(\mathrm{S}-b$-MMA) were observed. This indicated that cross-linked

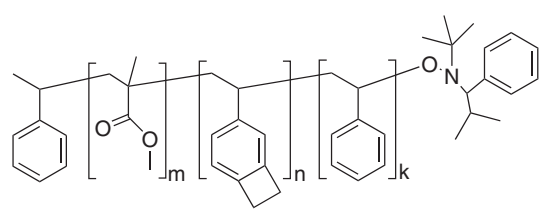

(a) P(S-r-BCB-r-MMA)
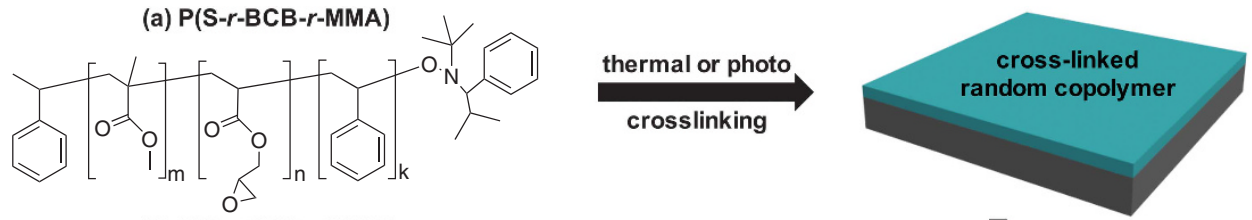

(b) P(S-r-GMA-r-MMA)

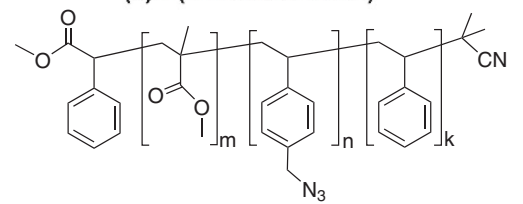

(c) $\mathrm{P}\left(\mathrm{S}-r-\left(\mathrm{S}-\mathrm{N}_{3}\right)-r-\mathrm{MMA}\right)$
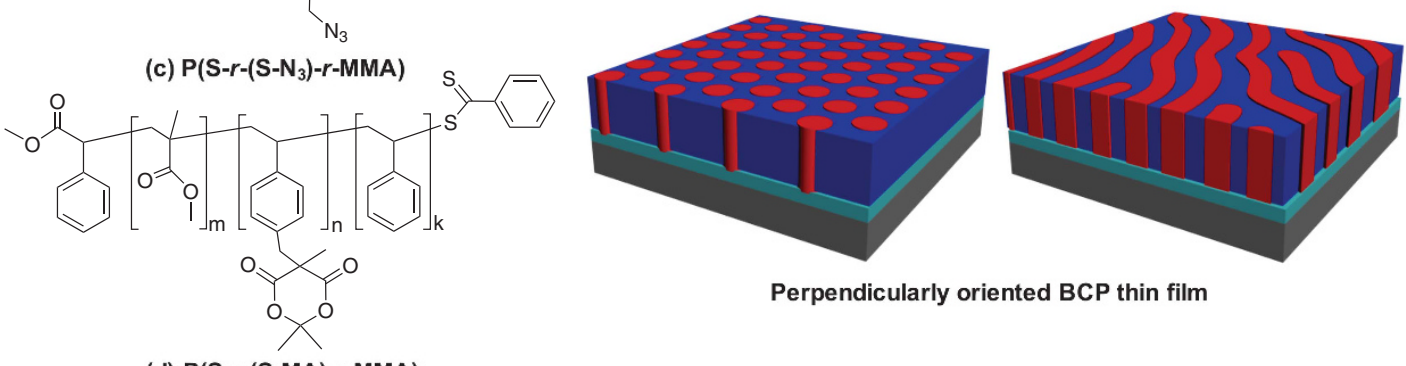

Perpendicularly oriented BCP thin film

(d) P(S-r-(S-MA)-r-MMA)

Figure 1 Schematic illustration of the substrate neutralization with various cross-linkable random copolymers for the perpendicular orientation of a $\mathrm{P}(\mathrm{S}-b-\mathrm{MMA})$ thin film. BCP, block copolymer; GMA, glycidyl methacrylate; $\mathrm{P}(\mathrm{S}-b-\mathrm{MMA})$, polystyrene-block-poly(methyl methacrylate); $r$, random. 

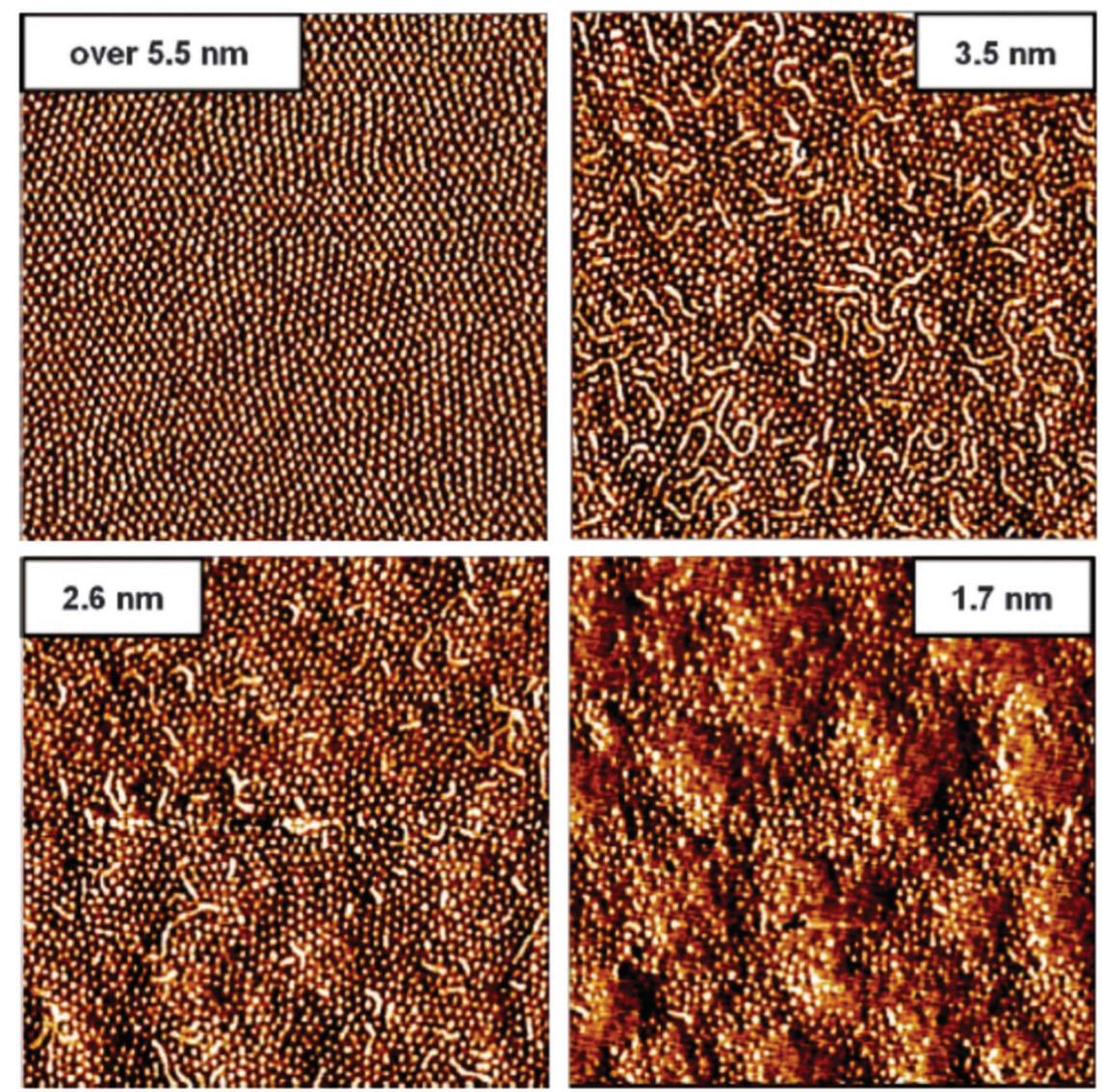

Figure 2 Phase images measured by scanning probe microscopy (SPM) of cylinder-forming $\mathrm{P}(\mathrm{S}-\mathrm{b}$-MMA) thin films on cross-linked $\mathrm{P}(\mathrm{S}-\mathrm{r}$-BCB- $r$-MMA) random copolymer mats with various thicknesses. Reprinted with permission from Ryu et al. ${ }^{29}$ Copyright 2007, American Chemical Society. BCB, benzocyclobutene; $\mathrm{P}(\mathrm{S}-b-\mathrm{MMA})$, polystyrene-block-poly(methyl methacrylate); $r$, random.

$\mathrm{P}(\mathrm{S}-r$-BCB- $r$-MMA) films of at least $5.5 \mathrm{~nm}$ can effectively mediate interfacial interactions between $\mathrm{P}(\mathrm{S}-b-\mathrm{MMA})$ and the substrate. However, as the thickness of the $\mathrm{P}(\mathrm{S}-r$-BCB- $r$-MMA) film decreases below $5.5 \mathrm{~nm}$, the fraction of parallel cylindrical microdomains increases. Furthermore, it was also demonstrated that the $\mathrm{P}(\mathrm{S}-r$-BCB- $r$-MMA) cross-linked layer can be successfully applied to various substrates, such as $\mathrm{Au}, \mathrm{Al}, \mathrm{Si}_{3} \mathrm{~N}_{4}$, Kapton and polyethylene terephthalate. ${ }^{28}$

\section{GMA-BASED CROSS-LINKABLE RANDOM COPOLYMER}

Although the BCB-based cross-linking chemistry is very effective, this approach suffers from the fact that the $\mathrm{BCB}$ monomer is not commercially available and requires a high cross-linking temperature. As an alternative, Gopalan and colleagues used two random copolymer brushes containing acryloyl or glycidyl groups and demonstrated that they can be cross-linked by UV irradiation with the aid of a photoinitiator or a photoacid generator; the resultant material acted as a neutral layer for $\mathrm{P}(\mathrm{S}-b-\mathrm{MMA}){ }^{30}$ Later, they systematically investigated a cross-linkable random copolymer of GMA incorporated with styrene and MMA, P(S-r-GMA-r-MMA) (Figure $1 \mathrm{~b}$ ), as a function of different styrene $(50-70 \mathrm{~mol} \%)$ and GMA fractions (14 mol\%). ${ }^{31}$ The various $\mathrm{P}(\mathrm{S}-r$-GMA- $r$-MMA) random copolymers were coated onto a silicon wafer and thermally annealed at either 160 or $230{ }^{\circ} \mathrm{C}$ under nitrogenous conditions. They found that P(S-r-GMA$r$-MMA) thin films required cross-linking times of $3 \mathrm{~h}$ at $160{ }^{\circ} \mathrm{C}$ and $60 \mathrm{~min}$ at $230^{\circ} \mathrm{C}$, regardless of the molecular weight or the GMA content. In addition, the cross-linking efficiency, as determined by the difference in film thickness before and after the rinsing step, increases as the mole fraction of GMA in the random copolymer increases from 1 to $4 \mathrm{~mol} \%$. Furthermore, random copolymers with higher molecular weights and equimolar GMA content showed faster cross-linking kinetics and slightly thicker final film thicknesses than those with lower molecular weights. After the cross-linking test, they systematically characterized the compositional ranges of the $\mathrm{P}$ (S-r-GMA- $r$-MMA) random copolymer layers for perpendicular orientation of three kinds of $\mathrm{P}(\mathrm{S}-b-\mathrm{MMA})$ BCPs: symmetric $\mathrm{P}(\mathrm{S}-b$-MMA $)\left(M_{\mathrm{n}}=104 \mathrm{~kg} \mathrm{~mol}^{-1}, \emptyset=1.09, f_{\mathrm{PS}}=0.53\right)$, asymmetric PMMA cylinder-forming $\mathrm{P}(\mathrm{S}-b-\mathrm{MMA})\left(M_{\mathrm{n}}=71.4 \mathrm{~kg} \mathrm{~mol}^{-1}, Ð=1.06\right.$, $\left.f_{\mathrm{PS}}=0.73\right)$ and asymmetric PS cylinder-forming $\mathrm{P}(\mathrm{S}-b$-MMA) $\left(M_{\mathrm{n}}=70.7 \mathrm{~kg} \mathrm{~mol}^{-1}, \emptyset=1.07, f_{\mathrm{PS}}=0.31\right)$, as shown in Figure 3 . Furthermore, they compared the effective minimum thickness of the cross-linked neutral layers when the mole fraction of GMA was varied from 1 to $4 \mathrm{~mol} \%$. In the case of P(S-r-GMA-r-MMA) with $1 \mathrm{~mol} \%$ of GMA, the minimum effective thickness for inducing the perpendicular orientation of the BCP thin films was $\sim 6 \mathrm{~nm}$. In contrast, even $2.3 \mathrm{~nm}$ of a P(S-r-GMA-r-MMA) layer with $4 \mathrm{~mol} \%$ of GMA could induce perpendicularly oriented microdomains. This result indicates that P(S-r-GMA-r-MMA) with $4 \mathrm{~mol} \%$ of GMA can effectively prevent the interpenetration of the $\mathrm{BCP}$ and thus prevent preferential interfacial interactions with the substrate.

\section{AZIDO-BASED CROSS-LINKABLE RANDOM COPOLYMER}

In addition to BCB- and GMA-based cross-linking chemistries, the azido group was incorporated into $\mathrm{P}(\mathrm{S}-\mathrm{r}-\mathrm{MMA})$ by Bang et al. ${ }^{32}$ 
a

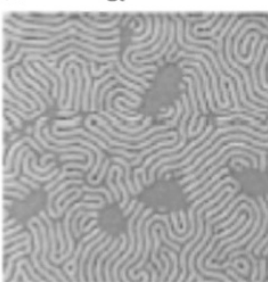

b

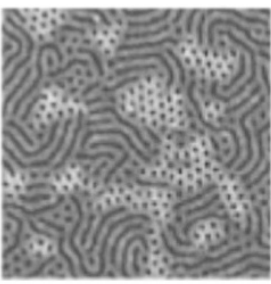

C

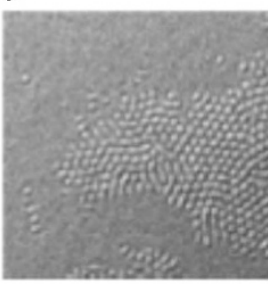

0.56
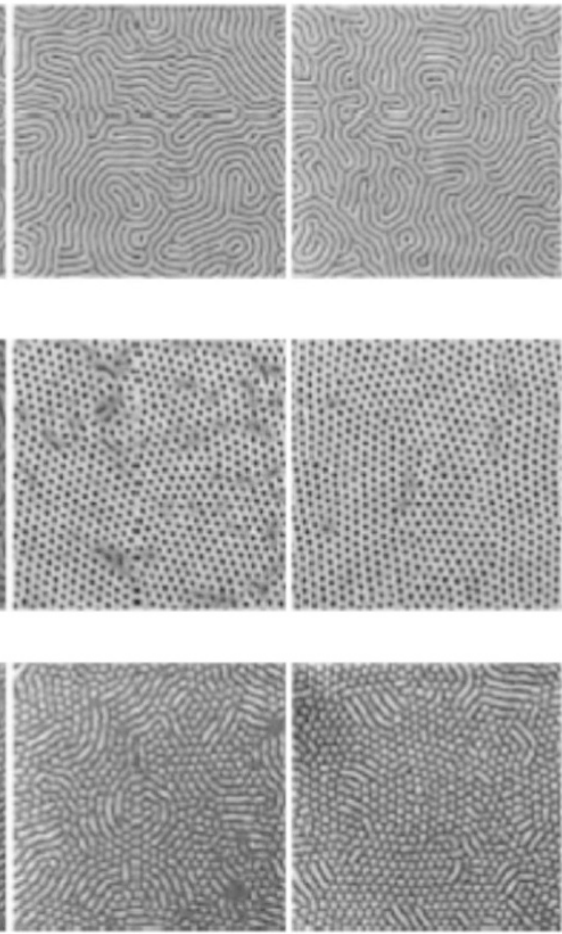

0.61

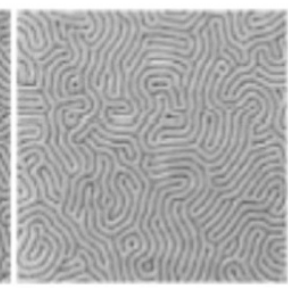

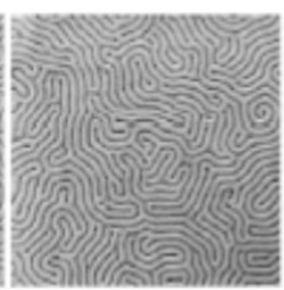
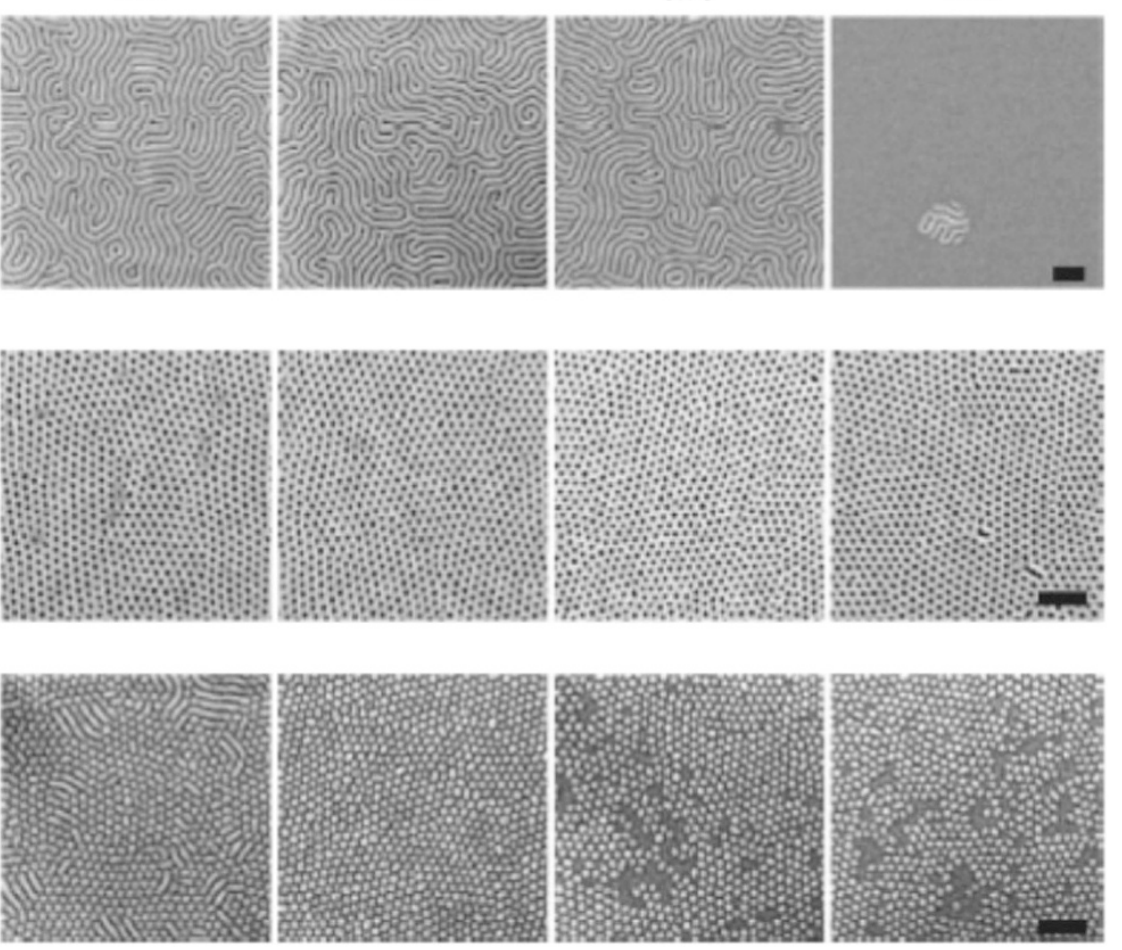

Figure 3 Top view SEM images of BCP thin films: (a) lamellae-forming P(S-b-MMA), (b) PMMA cylinder-forming P(S-b-MMA) and (c) PS cylinder-forming $\mathrm{P}(\mathrm{S}-b-\mathrm{MMA})$. Black scale bars are $200 \mathrm{~nm}$. Reprinted with permission from Han et al. ${ }^{31}$ Copyright 2010, American Chemical Society. BCP, block copolymer; $\mathrm{P}(\mathrm{S}-b-\mathrm{MMA})$, polystyrene-block-poly(methyl methacrylate); SEM, scanning electron microscope.

The azido group can be easily introduced by nucleophilic displacement of alkyl halides from commercially available monomers, such as 4-vinylbenzyl chloride, and activated by either heat or UV irradiation. As shown in Figure 1c, they synthesized azide-based random copolymer, $\mathrm{P}\left(\mathrm{S}-r\right.$ - $\left(\mathrm{S}-\mathrm{N}_{3}\right)-r$-MMA), containing $3 \mathrm{~mol} \%$ azide $\left(\mathrm{N}_{3}\right)$ units along the backbone via reversible addition fragmentation chain transfer polymerization of styrene, MMA and 4-vinylbenzyl chloride. The azido group has the following advantages: chemical stability before activation and easy handling under ambient conditions. On the basis of the neutral composition of a $\mathrm{P}(\mathrm{S}-r$-MMA) random copolymer, ${ }^{22-24}$ the composition of PMMA in the random copolymer was fixed at $42 \mathrm{~mol} \%$ and the others at a total of $58 \mathrm{~mol} \%$ because the azido unit has a chemical structure similar to styrene. In addition, the molecular weight of $\mathrm{P}\left(\mathrm{S}-r-\left(\mathrm{S}-\mathrm{N}_{3}\right)-r\right.$-MMA) was controlled over a range of $20-100 \mathrm{~kg} \mathrm{~mol}^{-1}$ to observe its effects on the cross-linking efficiency and density. To prepare the neutralized surface, toluene solutions of $\mathrm{P}\left(\mathrm{S}-r\right.$ - $\left(\mathrm{S}-\mathrm{N}_{3}\right)-r$-MMA) were spin casted onto silicon wafers to give $\sim 11$-nm-thick films. The films were then exposed to UV irradiation $(\lambda=254 \mathrm{~nm})$ under vacuum to photoinduce cross-linking. It should be noted that irradiation with a UV wavelength of $\lambda=254 \mathrm{~nm}$ can cause photo-degradation of the PMMA block in the $\mathrm{P}(\mathrm{S}-b-\mathrm{MMA})$ thin films. However, in the case of the $\mathrm{P}(\mathrm{S}-r$-MMA) random copolymer, photo-degradation of the PMMA blocks is efficiently retarded by a small fraction of PS in the random copolymer because the main photo-absorbing species in the $\mathrm{P}\left(\mathrm{S}-r\right.$-MMA) is $\mathrm{PS}$, which has a screening effect. ${ }^{49}$ Regardless of UV intensity, it was found that the thickness of the cross-linked layers, after washing with a good solvent, reached a constant value of 9-10 nm after $5 \mathrm{~min}$ of UV irradiation. This pointed to the high cross-linking efficiency of the azido group and a fast and facile reaction, which is comparable to $\mathrm{BCB}$ and GMA cross-linking chemistries. To confirm whether $\mathrm{P}\left(\mathrm{S}-r\right.$ - $\left(\mathrm{S}-\mathrm{N}_{3}\right)-r$-MMA) cross-linked layers effectively control the interfacial interactions with the substrates, cylinder-forming $\mathrm{P}(\mathrm{S}-b$-MMA $)\left(M_{\mathrm{n}}=76 \mathrm{~kg} \mathrm{~mol}^{-1}, \quad D=1.06\right)$ was spin coated onto these cross-linked layers and subsequently thermally annealed at $170{ }^{\circ} \mathrm{C}$ for $12 \mathrm{~h}$. In this experiment, the UV exposure time to prepare the $\mathrm{P}\left(\mathrm{S}-r-\left(\mathrm{S}-\mathrm{N}_{3}\right)-r\right.$-MMA $)$ cross-linked layer was varied up to $30 \mathrm{~min}$. As shown in Figure $4 \mathrm{a}$, with a short UV exposure, the $\mathrm{P}(\mathrm{S}-b-\mathrm{MMA}) \mathrm{BCP}$ thin film showed perpendicularly oriented cylindrical microdomains with excellent ordering. However, as the UV exposure time increases, the BCP thin film shows significant defects, which are attributable to side reactions of the random copolymer layer induced by the longer UV exposure time. In addition to UV cross-linking, the azido group can be cross-linked by heat; thus, the random copolymer-coated substrates were thermally annealed at $250^{\circ} \mathrm{C}$ under a flow of nitrogen. No decrease in the final film thickness was observed even after $1 \mathrm{~min}$ of thermal annealing, which is similar to the BCB system. In addition, the thermally cross-linked random copolymer layer could effectively neutralize the substrate, and therefore, perpendicularly oriented cylindrical microdomains of $\mathrm{P}(\mathrm{S}-b-\mathrm{MMA})$ were successfully induced. Because the azide group can be cross-linked by UV irradiation, the $\mathrm{P}\left(\mathrm{S}-r-\left(\mathrm{S}-\mathrm{N}_{3}\right)-r\right.$-MMA) random copolymer could be applied in conjunction with 'top-down' lithography, leading to a patterned neutral layer. Both cylinder-forming $\mathrm{P}(\mathrm{S}-b-\mathrm{MMA})$ and lamellaeforming $\mathrm{P}\left(\mathrm{S}-b\right.$-MMA) $\left(M_{\mathrm{n}}=45 \mathrm{~kg} \mathrm{~mol}^{-1}, \emptyset=1.07\right)$ were coated on the patterned layer. As a result, a perpendicularly oriented microstructure was observed on the UV exposed area (neutral layer), while a parallel orientation including a 'hole and island' structure can be seen on the unexposed area where the neutral layer was washed away (Figures $4 \mathrm{~b}$ and $\mathrm{c}$ ). 
a
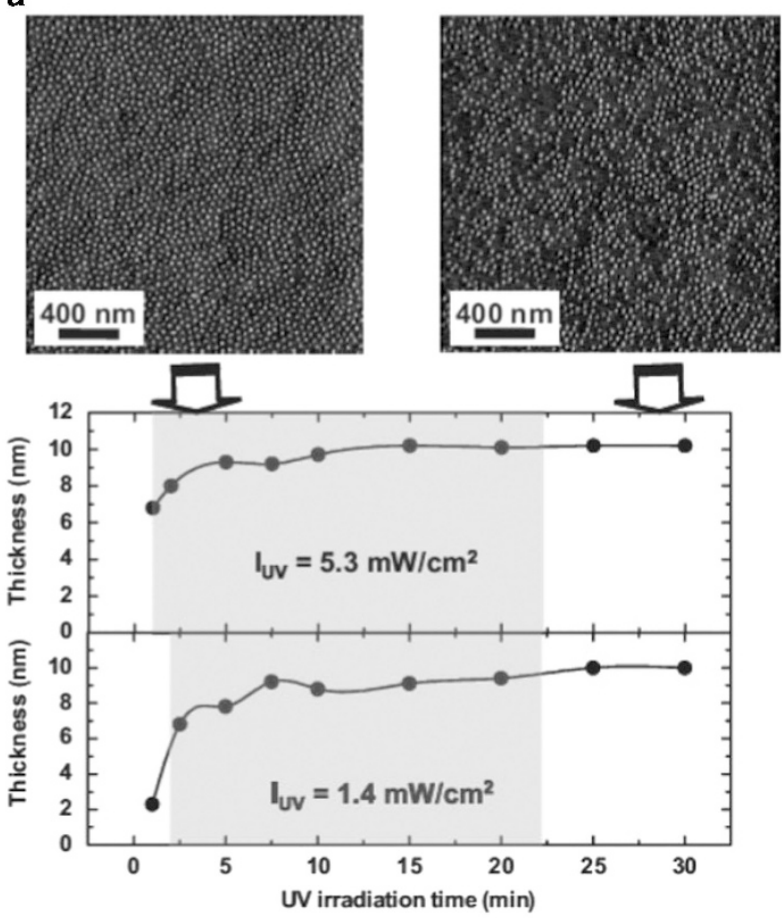

b

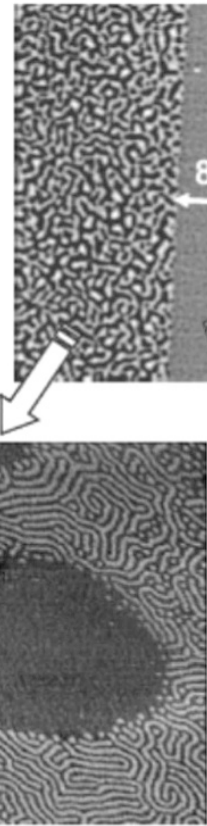

C
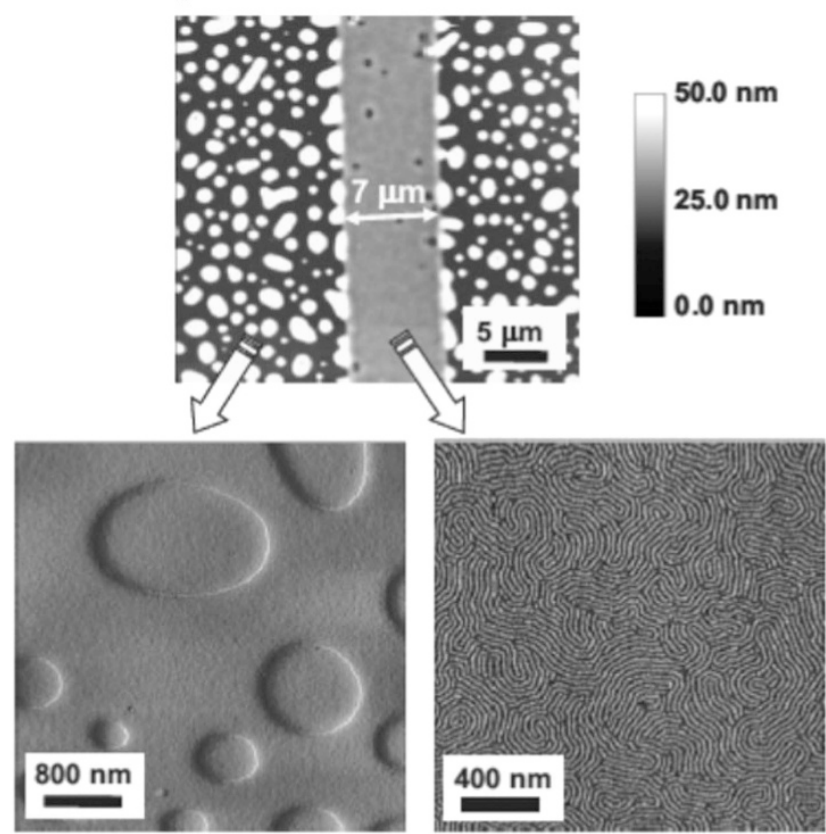

Figure 4 (a) Variation of cross-linked $\mathrm{P}\left(\mathrm{S}-\mathrm{r}-\left(\mathrm{S}-\mathrm{N}_{3}\right)-r-\mathrm{MMA}\right)$ film thicknesses as a function of UV irradiation time at two different UV intensities with the representative AFM phase images of cylinder-forming $\mathrm{P}(\mathrm{S}-b-\mathrm{MMA}$ ) thin films; (b) cylinder and (c) lamellae-forming $\mathrm{P}(\mathrm{S}-b$-MMA) thin films on the patterned random copolymer layer. Reprinted with permission from Bang et al. ${ }^{32}$ Copyright 2007, Wiley. AFM, atomic force microscopy; P(S- $b$-MMA), polystyrene-block-poly(methyl methacrylate); $r$, random.

\section{KETENE-BASED CROSS-LINKABLE RANDOM COPOLYMER}

Although the azide-based random copolymer exhibits a facile and rapid cross-linking chemistry, it still suffers from multiple postpolymerization steps, unwanted surface defects after long irradiation times, and limited covalent adhesion to the underlying substrate. To overcome these issues, Meldrum's acid ${ }^{50}$-incorporated random copolymers have been introduced for surface neutralization. ${ }^{33}$
Recently, several studies using Meldrum's acid as a building block for thermal access to the valuable ketene functional group have been reported. ${ }^{51-55}$ These studies demonstrated that ketene chemistry can provide not only cross-linking via dimerization but also functionalization via nucleophilic addition and covalent bonding to the substrate. Ketene chemistry is therefore suitable for fabricating a crosslinkable random copolymer that covalently attaches to the substrate. A 
Meldrum's acid-containing comonomer (S-MA) can be easily synthesized by a one-step reaction from two commercial reactants, 5-methyl Meldrum's acid and 4-vinylbenzyl chloride. P(S-r-(S-MA)- $r$-MMA) $\left(M_{\mathrm{n}}=20-30 \mathrm{~kg} \mathrm{~mol}^{-1}, Ð=1.2\right)$ random copolymers containing 3, 5 and $10 \mathrm{~mol} \%$ of S-MA synthesized via reversible addition fragmentation chain transfer polymerization were systematically investigated by varying factors such as the concentration of S-MA in the random copolymer, cross-linking temperature and cross-linking time to optimize the performance of the neutralization layer. As shown in Figure $1 \mathrm{~d}$, because of the similarity in chemical structure between styrene and the S-MA unit, the composition of styrene and S-MA in the random copolymer was kept at $55 \mathrm{~mol} \%$, and MMA composed the remaining percentage, $45 \mathrm{~mol} \%$. The random copolymers were spin casted onto silicon wafers, providing random copolymer thin films with a thickness of $11.5-13 \mathrm{~nm}$, and subsequently were crosslinked at various temperatures over a period of $1 \mathrm{~h}$. To confirm the surface neutralization, lamellae-forming $\mathrm{P}(\mathrm{S}-b-\mathrm{MMA}) \quad \mathrm{BCP}$ $\left(M_{\mathrm{n}}=74 \mathrm{~kg} \mathrm{~mol}^{-1}, f_{\mathrm{PS}}=0.54\right)$ was spin casted onto the substrate coated with the cross-linked random copolymer layer. When the random copolymer layers were thermally cross-linked at $200^{\circ} \mathrm{C}$, the microdomains of $\mathrm{P}(\mathrm{S}-b-\mathrm{MMA})$ were mixed with parallel and perpendicular orientations on the random copolymer layer, regardless of the mole fraction of S-MA in P(S-r-(S-MA)-r-MMA). This demonstrated that a $200{ }^{\circ} \mathrm{C}$ cross-linking temperature was insufficient to produce an effective neutral layer. However, as shown in Figure 5, when the crosslinking temperature was increased up to 230 or $250{ }^{\circ} \mathrm{C}$ and annealed for less than $1 \mathrm{~min}$, perpendicularly oriented microdomains of the $\mathrm{P}$
(S- $b$-MMA) BCP were developed regardless of the S-MA concentration. Owing to the covalent bonding of the random copolymer to the substrate via nucleophilic addition of ketene to silanol groups on the wafer surface, the thickness of the cross-linked layer did not change even after sonication for $1 \mathrm{~h}$ in benzene, a good solvent. In addition, there were no changes in the lateral ordering of $\mathrm{P}(\mathrm{S}-b-\mathrm{MMA})$ on the sonicated $\mathrm{P}(\mathrm{S}-r$-(S-MA)- $r$-MMA) random copolymer layer. In contrast, the thickness of the azido-based random copolymer is reduced when the film was sonicated for less than $1 \mathrm{~min}$, resulting in a mixed orientation of parallel and perpendicular microdomains in the subsequently coated $\mathrm{P}(\mathrm{S}-b$-MMA) thin film layer. These results demonstrate that a ketene-based cross-linking approach for fabricating a neutral layer provides enhanced neutralization performance with great adhesion compared with the previous systems. Furthermore, the applicability of this system is highlighted by the fact that it can be applied to other surfaces such as $\mathrm{Al}_{2} \mathrm{O}_{3} .{ }^{33,51}$

\section{CONCLUSIONS}

In this review, we discussed recent developments in the orientation control of BCP thin films using cross-linkable random copolymers for surface neutralization. Cross-linkable random copolymers can form ultrathin layers on various substrates and neutralize the substrates to fabricate perpendicularly oriented BCP microstructures. First, the BCB-based random copolymer was used as a thermally cross-linked neutral layer to produce perpendicularly oriented $\mathrm{P}(\mathrm{S}-b$-MMA) $\mathrm{BCP}$ microdomains. The BCB-based random copolymer was shown to produce cross-linked films on various substrates and allowed control
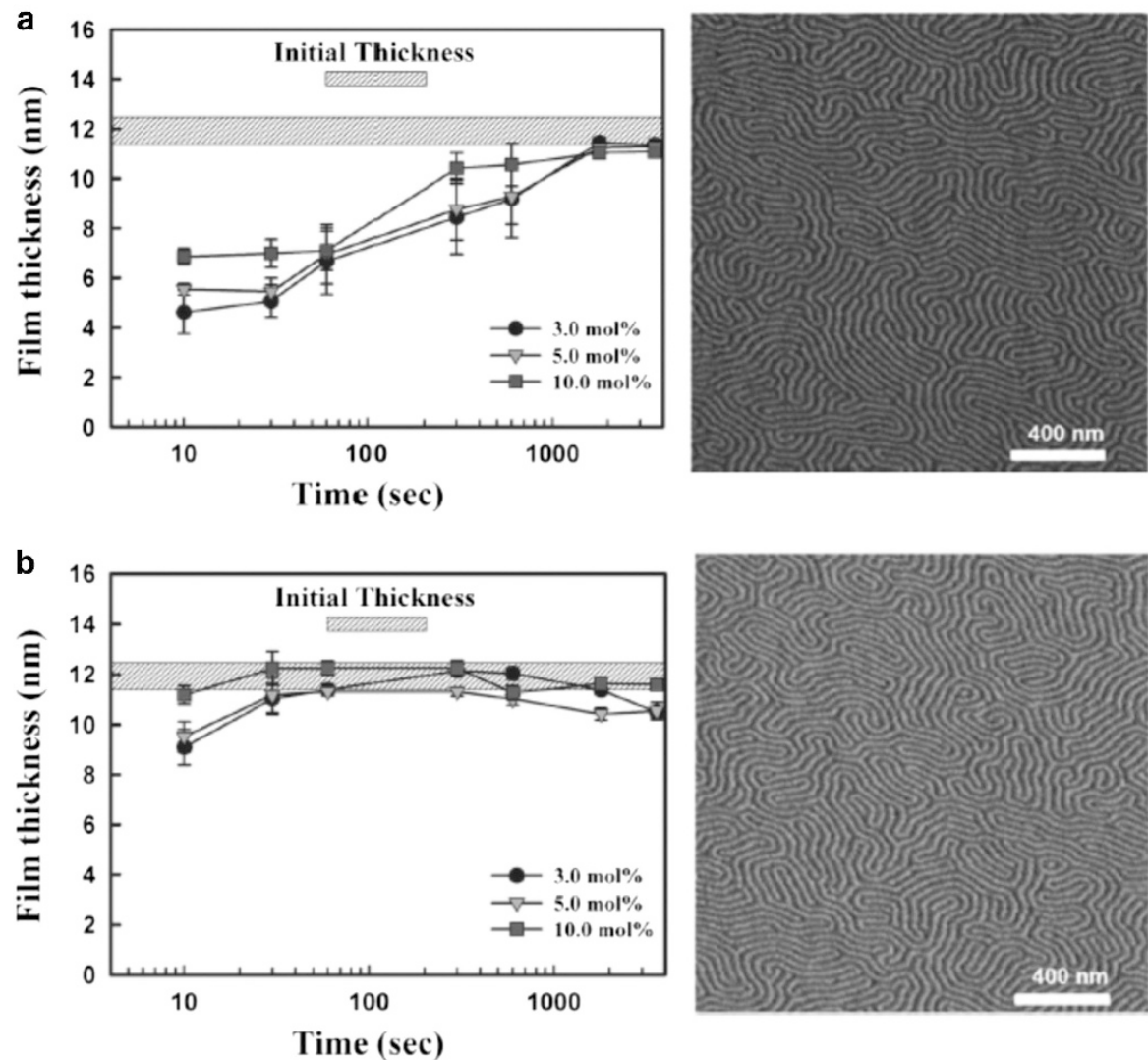

Figure 5 Cross-linked thickness of $\mathrm{P}(\mathrm{S}-\mathrm{r}-(\mathrm{S}-\mathrm{MA})-\mathrm{r}-\mathrm{MMA})$ thin films as a function of cross-linking time and representative AFM images of the overlying lamellae-forming $\mathrm{P}\left(\mathrm{S}-b-\mathrm{MMA}\right.$ ) after cross-linking at (a) 230 and (b) $250{ }^{\circ} \mathrm{C}$; P(S-r-(S-MA)-r-MMA) layers in the AFM images contained 3 mol\% of S-MA and were cross-linked for $10 \mathrm{~s}$. Reprinted with permission from Jung et $a l^{33}$ Copyright 2013, Wiley. AFM, atomic force microscopy; P(S- $b$-MMA), polystyrene-block-poly(methyl methacrylate); $r$, random. 
of interfacial interactions with a good cross-linking efficiency. However, drawbacks of the BCB cross-linkable monomer are that it is commercially unavailable and difficult to synthesize. Then, GMA and azido groups were used as cross-linkers in $\mathrm{P}(\mathrm{S}-\mathrm{r}-\mathrm{MMA})$ random copolymers for surface neutralization. Compared with the BCB-based system, both of these cross-linkable groups are commercially available and provide facile cross-linking conditions using either heat or UV irradiation with the aid of a photoinitiator or a photoacid generator. In particular, the azide group can be cross-linked by heat or UV exposure without the aid of any additional photoinitiators, allowing patterned neutral layers by UV lithography. Recently, random copolymers using ketene chemistry were developed, which produce an effective neutral layer and exhibit excellent adhesion within a very short thermal crosslinking time. These studies provide a simple route for controlling the microdomain orientation of BCP thin films via surface neutralization with various cross-linkable random copolymers and offer significant promise as a platform for the further development of BCP lithography.

\section{CONFLICT OF INTEREST}

The authors declare no conflict of interest.

\section{ACKNOWLEDGEMENTS}

This work was funded by the National Research Foundation of Korea grant, which was funded by the Korea government (MSIP; Nos. 2015R1A2A2A01006008, 2012M3A7B4049863 and 2012M3A7B4035323) and also by the Global Frontier R\&D Program (No. 2013M3A6B1078869) of the Center for Hybrid Interface Materials (HIM), which was funded by the Ministry of Science, ICT \& Future Planning.

1 Bang, J., Jeong, U., Ryu, D. Y., Russell, T. P. \& Hawker, C. J. Block copolymer nanolithography: translation of molecular level control to nanoscale patterns. Adv. Mater. 21, 4769-4792 (2009).

2 Lazzari, M. \& López-Quintela, M. A. Block copolymers as a tool for nanomaterial fabrication. Adv. Mater. 15, 1583-1594 (2003).

3 Hawker, C. J. \& Russell, T. P. Block copolymer lithography: merging "bottom-up" with "top-down" processes. MRS Bull. 30, 952-966 (2005).

4 Segalman, R. A. Patterning with block copolymer thin films. Mat. Sci. Eng. R 48, 191-226 (2005)

5 Phillip, W. A., O'Neill, B., Rodwogin, M., Hillmyer, M. A. \& Cussler, E. L. Self-assembled block copolymer thin films as water filtration membranes. ACS Appl. Mater. Interfaces 2, 847-853 (2010).

6 Hong, A. J., Liu, C.-C., Wang, Y., Kim, J., Xiu, F., Ji, S., Zou, J., Nealey, P. F. \& Wang, K. L. Metal nanodot memory by self-assembled block copolymer lift-off. Nano Lett. 10, 224-229 (2010).

7 Kim, M., Safron, N. S., Han, E., Arnold, M. S. \& Gopalan, P. Fabrication and characterization of large-area, semiconducting nanoperforated graphene materials. Nano Lett. 10, 1125-1131 (2010).

8 Fan, H. J., Werner, P. \& Zacharias, M. Semiconductor nanowires: from self-organization to patterned growth. Small 2, 700-717 (2006).

9 Fasolka, M. J. \& Mayes, A. M. Block copolymer thin films: physics and applications. Annu. Rev. Mater. Res. 31, 323-355 (2001)

10 Black, C. T., Ruiz, R., Breyta, G., Cheng, J. Y., Colburn, M. E., Guarini, K. W., Kim, H. C. \& Zhang, Y. Polymer self assembly in semiconductor microelectronics. IBM J. Res. Dev. 51, 605-633 (2007).

11 Cheng, J. Y., Ross, C. A., Smith, H. I. \& Thomas, E. L. Templated self-assembly of block copolymers: top-down helps bottom-up. Adv. Mater. 18, 2505-2521 (2006).

12 Jung, H., Hwang, D., Kim, E., Kim, B.-J., Lee, W. B., Poelma, J. E., Kim, J., Hawker, C. J., Huh, J., Ryu, D. Y. \& Bang, J. Three-dimensional multilayered nanostructures with controlled orientation of microdomains from cross-linkable block copolymers. ACS Nano 5, 6164-6173 (2011).

13 Hawker, C. J. \& Wooley, K. L. The convergence of synthetic organic and polymer chemistries. Science 309, 1200-1205 (2005).

14 Stoykovich, M. P., Müller, M., Kim, S. O., Solak, H. H., Edwards, E. W., de Pablo, J. J. \& Nealey, P. F. Directed assembly of block copolymer blends into nonregular device-oriented structures. Science 308, 1442-1446 (2005).

15 Kim, E., Ahn, H., Park, S., Lee, H., Lee, M., Lee, S., Kim, T., Kwak, E.-A., Lee, J. H., Lei, X., Huh, J., Bang, J., Lee, B. \& Ryu, D. Y. Directed assembly of high molecular weight block copolymers: highly ordered line patterns of perpendicularly oriented lamellae with large periods. ACS Nano 7, 1952-1960 (2013).
16 Choi, E., Park, S., Ahn, H., Lee, M., Bang, J., Lee, B. \& Ryu, D. Y. Substrate-independent lamellar orientation in high-molecular-weight polystyrene-bpoly(methyl methacrylate) films: neutral solvent vapor and thermal annealing effect. Macromolecules 47, 3969-3977 (2014).

17 Segalman, R. A., Yokoyama, H. \& Kramer, E. J. Graphoepitaxy of spherical domain block copolymer films. Adv. Mater. 13, 1152-1155 (2001).

18 Kim, S. O., Solak, H. H., Stoykovich, M. P., Ferrier, N. J., de Pablo, J. J. \& Nealey, P. F. Epitaxial self-assembly of block copolymers on lithographically defined nanopatterned substrates. Nature 424, 411-414 (2003).

19 Liu, P.-H., Thébault, P., Guenoun, P. \& Daillant, J. Easy orientation of diblock copolymers on self-assembled monolayers using UV irradiation. Macromolecules 42, 9609-9612 (2009).

20 Mansky, P., Russell, T., Hawker, C., Mays, J., Cook, D. \& Satija, S. Interfacial segregation in disordered block copolymers: effect of tunable surface potentials. Phys. Rev. Lett. 79, 237 (1997).

21 Huang, E., Mansky, P., Russell, T. P., Harrison, C., Chaikin, P. M., Register, R. A. Hawker, C. J. \& Mays, J. Mixed lamellar films: evolution, commensurability effects, and preferential defect formation. Macromolecules 33, 80-88 (2000).

22 Huang, E., Rockford, L., Russell, T. P. \& Hawker, C. J. Nanodomain control in copolymer thin films. Nature 395, 757-758 (1998).

23 Huang, E., Pruzinsky, S., Russell, T., Mays, J. \& Hawker, C. Neutrality conditions for block copolymer systems on random copolymer brush surfaces. Macromolecules $\mathbf{3 2}$, 5299-5303 (1999).

24 Mansky, P., Liu, Y., Huang, E., Russell, T. \& Hawker, C. Controlling polymer-surface interactions with random copolymer brushes. Science 275, 1458-1460 (1997).

25 Anastasiadis, S. H., Russell, T. P., Satija, S. K. \& Majkrzak, C. F. Neutron reflectivity studies of the surface-induced ordering of diblock copolymer films. Phys. Rev. Lett. 62, 1852-1855 (1989).

26 Coulon, G., Russell, T. P., Deline, V. R. \& Green, P. F. Surface-induced orientation of symmetric, diblock copolymers - a secondary ion mass-spectrometry study. Macromolecules 22, 2581-2589 (1989).

27 Russell, T. P., Coulon, G., Deline, V. R. \& Miller, D. C. Characteristics of the surfaceinduced orientation for symmetric diblock PS/PMMA copolymers. Macromolecules 22 , 4600-4606 (1989).

28 Ryu, D. Y., Shin, K., Drockenmuller, E., Hawker, C. J. \& Russell, T. P. A generalized approach to the modification of solid surfaces. Science 308, 236-239 (2005).

29 Ryu, D. Y., Wang, J. Y., Lavery, K. A., Drockenmuller, E., Satija, S. K., Hawker, C. J. \& Russell, T. P. Surface modification with cross-linked random copolymers: minimum effective thickness. Macromolecules 40, 4296 (2007).

30 Han, E., In, I., Park, S. M., La, Y. H., Wang, Y., Nealey, P. F. \& Gopalan, P. Photopatternable imaging layers for controlling block copolymer microdomain orientation. Adv. Mater. 19, 4448-4452 (2007).

31 Han, E. \& Gopalan, P. Cross-linked random copolymer mats as ultrathin nonpreferential layers for block copolymer self-assembly. Langmuir 26, 1311-1315 (2010).

32 Bang, J., Bae, J., Löwenhielm, P., Spiessberger, C., Given-Beck, S. A., Russell, T. P. \& Hawker, C. J. Facile routes to patterned surface neutralization layers for block copolymer lithography. Adv. Mater. 19, $4552-4557$ (2007).

33 Jung, H., Leibfarth, F. A., Woo, S., Lee, S., Kang, M., Moon, B., Hawker, C. J. \& Bang, J. Efficient surface neutralization and enhanced substrate adhesion through ketene mediated crosslinking and functionalization. Adv. Funct. Mater. 23 1597-1602 (2013).

34 Bang, J., Kim, S. H., Drockenmuller, E., Misner, M. J., Russell, T. P. \& Hawker, C. J. Defect-free nanoporous thin films from abc triblock copolymers. J. Am. Chem. Soc. 128, 7622-7629 (2006)

$35 \mathrm{Kim}$, S. H., Misner, M. J., Xu, T., Kimura, M. \& Russell, T. P. Highly oriented and ordered arrays from block copolymers via solvent evaporation. Adv. Mater. 16, 226-231 (2004).

36 Thurn-Albrecht, T., DeRouchey, J., Russell, T. \& Jaeger, H. Overcoming interfacial interactions with electric fields. Macromolecules 33, 3250-3253 (2000).

37 Sivaniah, E., Hayashi, Y., lino, M., Hashimoto, T. \& Fukunaga, K. Observation of perpendicular orientation in symmetric diblock copolymer thin films on rough substrates. Macromolecules 36, 5894-5896 (2003).

$38 \mathrm{Kim}, \mathrm{T}$., Wooh, S., Son, J. G. \& Char, K. Orientation control of block copolymer thin films placed on ordered nanoparticle monolayers. Macromolecules 46, 8144-8151 (2013).

39 Bates, C. M., Seshimo, T., Maher, M. J., Durand, W. J., Cushen, J. D., Dean, L. M., Blachut, G., Ellison, C. J. \& Willson, C. G. Polarity-switching top coats enable orientation of sub-10-nm block copolymer domains. Science 338, 775-779 (2012).

$40 \mathrm{Kim}$, E., Kim, W., Lee, K. H., Ross, C. A. \& Son, J. G. A top coat with solvent annealing enables perpendicular orientation of sub-10-nm microdomains in Si-containing block copolymer thin films. Adv. Funct. Mater. 24, 6981-6988 (2014).

41 Yoo, M., Kim, S., Jang, S. G., Choi, S.-H., Yang, H., Kramer, E. J., Lee, W. B., Kim, B. J. \& Bang, J. Controlling the orientation of block copolymer thin films using thermally-stable gold nanoparticles with tuned surface chemistry. Macromolecules 44, 9356-9365 (2011).

42 Kim, S., Yoo, M., Kang, N., Moon, B., Kim, B. J., Choi, S.-H., Kim, J. U. \& Bang J. Nanoporous bicontinuous structures via addition of thermally-stable amphiphilic nanoparticles within block copolymer templates. ACS Appl. Mater. Interfaces 5, 5659-5666 (2013).

43 Kim, S., Yoo, M., Baettig, J., Kang, E.-H., Koo, J., Choe, Y., Choi, T.-L., Khan, A., Son, J. G. \& Bang, J. Perpendicularly oriented block copolymer thin films induced by neutral star copolymer nanoparticles. ACS Macro Lett 4, 133-137 (2015). 
44 Park, S. C., Kim, B. J., Hawker, C. J., Kramer, E. J., Bang, J. \& Ha, J. S. Controlled ordering of block copolymer thin films by the addition of hydrophilic nanoparticles. Macromolecules 40, 8119-8124 (2007).

45 Kim, S., Wang, H. S., Jang, S. G., Choi, S.-H., Kim, B. J. \& Bang, J. Nanoparticles as structure-directing agents for controlling the orientation of block copolymer microdomain in thin films. J. Polym. Sci. B Polym. Phys. 54, 118-127 (2016).

46 Guarini, K. W., Black, C. T. \& Yeung, S. H. I. Optimization of diblock copolymer thin film self assembly. Adv. Mater. 14, 1290-1294 (2002).

47 Thurn-Albrecht, T., Steiner, R., DeRouchey, J., Stafford, C. M., Huang, E., Bal, M., Tuominen, M., Hawker, C. J. \& Russell, T. P. Nanoscopic templates from oriented block copolymer films. Adv. Mater. 12, 787-791 (2000).

48 Ham, S., Shin, C., Kim, E., Ryu, D. Y., Jeong, U., Russell, T. P. \& Hawker, C. J. Microdomain orientation of ps-b-pmma by controlled interfacial interactions. Macromolecules 41, 6431-6437 (2008).

49 Torikai, A., Hozumi, A. \& Fueki, K. Photo-degradation of poly(styrene-comethylmethacrylate) in the solid phase. Polym. Degrad. Stab. 16, 13-24 (1986).
50 Meldrum, A. N. LIV. - a $\beta$-lactonic acid from acetone and malonic acid. J. Chem. Soc. 93, 598-601 (1908).

51 Leibfarth, F. A., Kang, M., Ham, M., Kim, J., Campos, L. M., Gupta, N., Moon, B. \& Hawker, C. J. A facile route to ketene-functionalized polymers for general materials applications. Nat. Chem. 2, 207-212 (2010).

52 Leibfarth, F. A., Schneider, Y., Lynd, N. A., Schultz, A., Moon, B., Kramer, E. J., Bazan, G. C. \& Hawker, C. J. Ketene functionalized polyethylene: control of cross-link density and material properties. J. Am. Chem. Soc. 132, 14706-14709 (2010).

53 Miyamura, Y., Park, C., Kinbara, K., Leibfarth, F. A., Hawker, C. J. \& Aida, T. Controlling volume shrinkage in soft lithography through heat-induced cross-linking of patterned nanofibers. J. Am. Chem. Soc. 133, 2840-2843 (2011).

54 Leibfarth, F. A., Wolffs, M., Campos, L. M., Delany, K., Treat, N., Kade, M. J., Moon, B. \& Hawker, C. J. Low-temperature ketene formation in materials chemistry through molecular engineering. Chem. Sci. 3, 766-771 (2012).

55 Tidwell, T. T. Ketene chemistry after 100 years: ready for a new century. Eur. J. Org. Chem. 2006, 563-576 (2006). 